\title{
Design of a teachers' training workshop for improving technology integration skills
}

\author{
Madhuri Mavinkurve ${ }^{1}$, Mahesh Patil ${ }^{2}$ \\ ${ }^{1}$ Deapartment of Electronics and communications, Thakur College of Engg and Technology, Kandivali, Mumbai \\ ${ }^{2}$ Department of Electrical Engineering, Indian Institute of Technology Bombay, Powai, Mumbai 400076, India. \\ ${ }^{1}$ mavinkurvemk@.gmail.com \\ ${ }^{2}$ mbpatil@ee.iitb.ac.in
}

\begin{abstract}
Educationists and researchers recommend integration of simulations in classrooms to promote student-centric constructivist learning. The simulations need to be carefully designed toward improvement of conceptual understanding of students. In this paper, we report on a training workshop for teachers with the specific goal of imparting simulation integration skills for classroom teaching. In the workshop, we used SEQUEL, a freely downloadable circuit simulator, and focused on electronic circuits taught typically at the second-year undergraduate level. We applied education technology principles as well as constructivist alignment methods to design the workshop. In particular, collaborative learning strategies such as think-pair-share and peer instruction were covered specifically for the intended simulation integration. Furthermore, application of the flipped classroom model in the context of circuit simulation was explained to the participants. We report on the workshop design in detail and report the impact of the training workshop on integration skills of the teachers. We found that teachers $(N=15)$ perceived the workshop to be useful in designing their aligned lesson plans. Teachers also reported their field study in which they found improved motivation of students to solve electronics circuit problems.
\end{abstract}

Keywords: Constructivist learning; Collaborative learning; Peer instruction; SEQUEL circuit simulator; Education technology

\section{INTRODUCTION}

Development of modern technologies has led to availability of a wide range of computer simulations (e.g., the PhET Sims, OSCAR Sims etc. [21]. Faculty members preferred to integrate these simulations due to its affordance such as possibility to manipulate variables, possibility to show different representations simultaneously, saving time, etc. The meta-analysis of research papers on learning effects of computer simulations [23] provided data on positive effects of learning gains. Even though simulations are useful and effective learning tools, their application in a classroom setting is a challenge. Most of the simulations need specific software or platforms. Faculty members need to select simulations from available existing simulations and these simulations may not be aligned with or may not satisfy their teaching requirements. Inappropriate use of simulations leads to no learning gains of students compared to lessons without simulations. In our research, we addressed the above issues by training faculty members to design simulations aligned with their instructional requirements. We selected the domain of electronic circuits and an easily accessible, freely downloadable circuit simulator "SEQUEL".

SEQUEL is a general-purpose circuit simulation program for electronic and power electronic circuits. In the present context, it is particularly useful since it can be downloaded and installed on any number of PCs. A large number of circuits are already incorporated in the simulator. The user can use these existing circuit files directly, modify them suitably, or prepare new circuit files if required. Teachers can design their simulations suitable for specific topics and goals. In the workshop reported here, we trained teachers to develop their own simulations. We also familiarized them with studentcentric active learning strategies. This work is a first step towards design guidelines for teacher training workshops to develop simulation integration skills among engineering teachers.

\section{RELATED WORK}

\subsection{Need for a technology integration workshop}

In recent years, use of simulations in classrooms or laboratories has increased due to affordances of technology such as possibility of immediate feedback to learners, virtual experimentation, and possibility to vary parameters, possibility to make invisible things visible [26],[3],[27]. Integration of simulation in classroom showed positive effects on learning of students such as improved conceptual understanding, improved exam scores, high learning gains, etc. [13],[24],[16]. Even though simulation is a useful technology tool, its integration in classroom is difficult for teachers, thus 
limiting its success [1],[5],[2],[7],[8],[10],[14]. One of the important challenges is that the teacher may lack knowledge about teaching approaches using technology [12],[17],[11].Furthermore, the teachers may find it difficult to match existing simulations with their teaching requirements [11] It was found that, if a technology tool such as simulation is applied passively in the classroom, does not improve learning gains [19]. One possible approach to make effective use of simulation for higher learning gains is training of teachers to design their own simulations suitable for their content and pedagogical requirements [15].

\subsection{Theoretical basis of workshop design}

In order to design training modules, we reviewed related work on various existing teacher training modules. Professional development of university faculty (PDUF) programme [4] included training components for online learning experience, innovative teaching practices, and cross-disciplinary communications. The training workshop on integration of ICT [6] included training related to multimedia resource design in ten different parts, beginning from familiarisation of multimedia resource to suitable design of multimedia resource for classroom integration. The Xanadu project focuses on training teachers to incorporate TEL based teaching methods in their instructions using ICT based learning materials such as simulations. In this project, teachers were trained for technological and methodological training by respective experts [25]. The ET4ET programme is designed for professional development of engineering teachers in India [18]. It is a large-scale faculty development programme on integration of education technology and the Attain-Align-Integrate (A2I) model. This model suggested the use of active learning and student-centric strategies. It also proposes alignment of learning objectives with instructional strategies [18] Meta-analysis of 225 studies reported in [9] indicated that application of active learning strategies in classroom in STEM education improves students' performance in exams and concept inventories. Based on this literature survey of training workshops, we concluded that our training modules should include components for technology design as well as training for active learning strategies aligned with the participating teachers' instructional goals.

\section{DESIGN AND IMPLEMENTATION OF TRAINING WORKSHOP}

\subsection{Research scope and research questions}

We scoped our research work to the domain of electronic circuits. Electronic Circuits is a core course in almost all streams of engineering. It includes application of various concepts and principles to specific circuits. Understanding of the circuit behavior and comprehending the concepts is generally a difficult task for learners. Simulations can support learners in connecting responses with actual circuits [22].

In this work, we used SEQUEL, a general-purpose circuit simulator developed at IIT Bombay [20]. It is particularly suitable for educational purposes since it can be freely downloaded and used by students and teachers in engineering colleges. SEQUEL has a tool box to construct different circuits and simulation options to obtain various performance parameters of the circuit. SEQUEL allows simulation of analog circuits, digital circuits, and power electronic circuits. It employs implicit numerical integration methods commonly used in other circuit simulators such as SPICE, PSIM, etc.

SEQUEL allows design of various simulations, but faculty members need to be trained to design their own simulations. The purpose of the workshop described here was to assist faculty members to develop and apply simulations in their classrooms. We evaluated the usefulness of the workshop through faculty perception and their confidence to apply the knowledge acquired during the workshop in their classrooms. In our study, we addressed the following research questions:

1. What is the perception of participants about SEQUEL integration workshops?

2. What is the confidence level of faculty members about the integration of SEQUEL in their classroom?

\subsection{SEQUEL integration workshop}

The training modules of the workshop included two components: (1) training for design of circuit simulations, (2) training for student-centric active learning strategies. We trained faculty to use features of SEQUEL such as construction of circuits, selection of output variables, assignment of analysis options, and finally, display of the output waveforms. This training was conducted for three days, starting with simple circuits and then going on to circuits with increased complexity in terms of circuit construction and analysis. There were two sessions of three hours devoted to active learning strategies. We covered peer instruction and flipped class room strategies. The training for active learning strategies was aligned with the A2I model. In this model, learning objectives are taught in the first session and instructional strategies in subsequent sessions. Sessions are also conducted in active learning mode. Two instructors were involved in the workshop, one with expertise in SEQUEL design simulations and the other with expertise in educational technology in the same domain, i.e., electronic circuits. In 
the following paragraph, we describe the content delivered by the trainers.

1. SEQUEL training modules: The first training module involved simulation of a relatively simple circuit (an RC circuit) using SEQUEL, with the goal of providing basic familiarity with the tool. The participants were given a demonstration first and were then asked to perform the simulation individually on their own. Any difficulties faced by the participants were resolved by workshop assistants as well as the instructor. Fig. 1 shows the specific circuit given to the participants for practice along with the expected outcome. Simulation of a circuit involves the following steps:

(a) Bring the required components (resistor, capacitor, voltage source, and ground) from the simulator library into the canvas, i.e., the central window meant for drawing the schematic

(b) Place the components suitably and connect them as required.

(c) Assign values to the components.

(d) Indicate to the simulator which variables should be stored as the simulation runs. This is accomplished by selecting "output variables" such as voltages and currents of interest.

(e) Select a "solve block" to indicate which analysis should be performed, viz., DC, transient (time-domain), or AC (frequencydomain).

(f) Assign values to the solve block parameters such as starting time, ending time, simulation time step, simulation method, etc.

(g) Specify the "output block," and within that the output file names, names of variables for each file.

(h) Run the simulation, view the waveforms, and compare with theoretically expected waveforms.

After all participants successfully simulated the sample circuit, topic-specific modules were taken up. These modules had a common theme: First, the participants were given a problem to work out on paper in about 30 minutes. After that, the solution was discussed by the instructor. Finally, the participants simulated the concerned circuit and checked the analytic solution against simulation results. The modules were designed around the following topics: diode circuits, BJT circuits, Op Amp circuits, Bode plots.
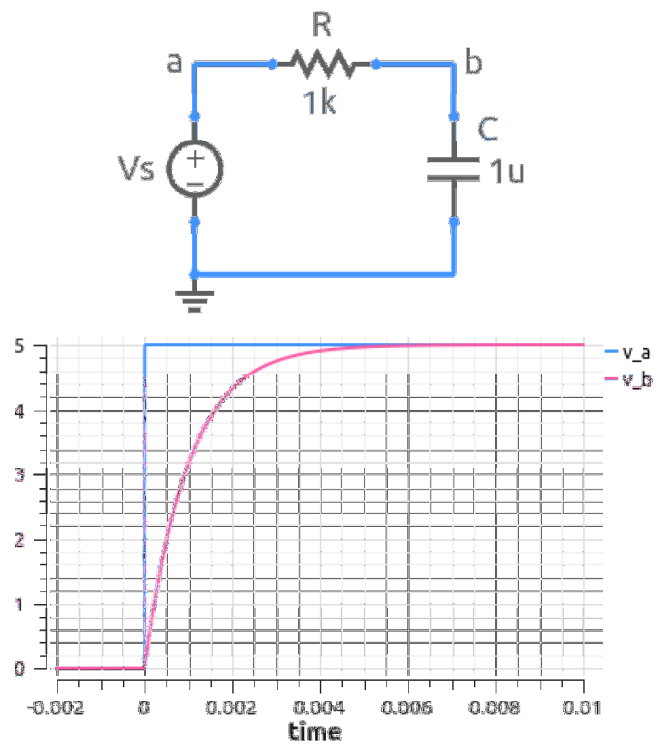

Fig.1. Circuit schematic for RC circuit and its transient response as obtained with SEQUEL.

\section{Teaching methodologies for active learning:}

We designed three sessions each of 1.5 to 2 hours duration to train faculty members with student-centric active learning strategies. The training program is shown in Fig. 2. We selected three modules for introducing active learning strategies. The first module was on learning objectives, the second on peer instruction, and the third on flipped classroom. We conducted these sessions using active learning (AL) instructional strategies. We actually demonstrated the AL instructional strategies through our sessions. Thus participants were not only provided information but they could see live demonstrations of these strategies. To introduce the participants to these strategies in each session, they were involved in designing activities for classroom using strategies explained to them.

A2I2-Two phases with SEQUEL simulator

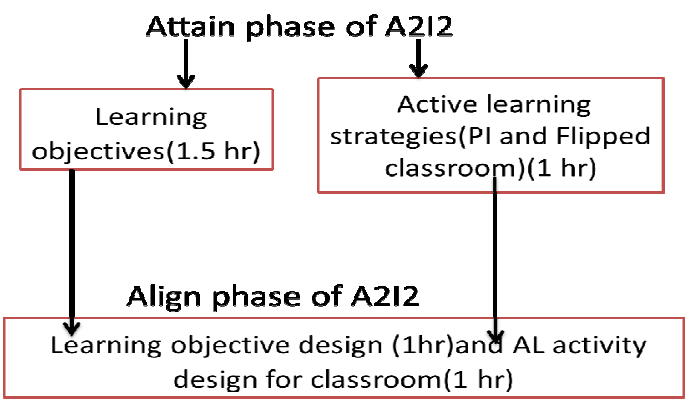

Fig. 2 Structure of training modules for active learning strategies 


\section{EVALUATION OF WORKSHOP}

There were $15(\mathrm{M}=9, \mathrm{~F}=6)$ participants from various engineering colleges in India, with a wide range of teaching experience, ranging from 1 to 28 years. All faculty members were from the domain of electronic circuits, having taught an electronics course once or several times, depending on their teaching experience. To test the usefulness of the training program, we collected and analyzed data on (1) perception of participants, (2) confidence to design SEQUEL based activity in classroom

We adapted survey items from the ET4ET project [18]. The five items addressed perception of participants (table 1) and 5 items addressed their confidence to design classroom activities (table 2) using SEQUEL. Cronbach $\alpha$ $(\alpha=0.8383)$ reliability coefficient was calculated for questions in this construct. The items contained a 4-point Likert scale from Strongly Disagree to Strongly Agree.

\section{A. Perception of participants about usefulness}

The perception survey result of participants about the SEQUEL training is shown in table 1.

Table 1: Participants perception on usefulness $(\mathrm{N}=15)$

\begin{tabular}{|l|l|l|l|c|}
\hline Items & SD & D & A & SA \\
\hline $\begin{array}{l}\text { I found the session on } \\
\text { Learning Objectives useful } \\
\text { for setting up my own } \\
\text { course objectives. }\end{array}$ & & & 7 & 8 \\
\hline $\begin{array}{l}\text { The session on Flipped } \\
\text { Classroom was useful for } \\
\text { me to identify when to use } \\
\text { flipped classroom in my } \\
\text { course. }\end{array}$ & & & 7 & 8 \\
\hline $\begin{array}{l}\text { The session on Flipped } \\
\text { Classroom (Mention date) } \\
\text { was useful for me to plan } \\
\text { for a flipped classroom } \\
\text { activity in my course. }\end{array}$ & & & 9 & 6 \\
\hline $\begin{array}{l}\text { I understand how to } \\
\text { appropriately incorporate } \\
\text { SEQUEL into instructional } \\
\text { practice. }\end{array}$ & & & & \\
\hline $\begin{array}{l}\text { After these sessions on } \\
\text { flipped classroom, I intend } \\
\text { to use Flipped classroom } \\
\text { back in my class }\end{array}$ & & 1 & 7 & 10 \\
\hline \begin{tabular}{l} 
Average \\
\hline
\end{tabular} & & 7 & 7 \\
\hline
\end{tabular}

It was found that $48 \%$ of the participants agreed and $48 \%$ strongly agreed that the sessions were useful for integration of active learning with SEQUEL in their classroom. One participant disagreed to intended use of flipped classroom.

\section{B. Confidence to design SEQUEL based activity in classroom}

The confidence survey results are shown in table 2 .

Table 2: Participants confidence to design of SEQUEL activities $(\mathrm{N}=15)$

\begin{tabular}{|c|r|r|r|r|}
\hline Items I can & SD & D & A & SA \\
\hline $\begin{array}{c}\text { Design SEQUEL } \\
\text { simulation to support } \\
\text { teaching and student } \\
\text { learning. }\end{array}$ & & & & \\
\hline $\begin{array}{c}\text { Design lessons that } \\
\text { utilize SEQUEL to } \\
\text { develop students' } \\
\text { higher order thinking } \\
\text { skills. }\end{array}$ & & & & \\
\hline $\begin{array}{c}\text { Teach lessons that } \\
\text { use SEQUEL to meet } \\
\text { the individual needs } \\
\text { of the students. }\end{array}$ & & & & \\
\hline $\begin{array}{c}\text { Find Video Lectures } \\
\text { to support my } \\
\text { Teaching and Student } \\
\text { Learning }\end{array}$ & & & & \\
\hline $\begin{array}{c}\text { Design lessons that } \\
\text { use Video Lectures to } \\
\text { develop Higher Order } \\
\text { thinking skills of my } \\
\text { students }\end{array}$ & & & & \\
\hline \begin{tabular}{c} 
Average \\
\hline
\end{tabular} & & & & \\
\hline
\end{tabular}

Results indicated that $57 \%$ faculty members agreed that they can design SEQUEL based active learning activities for their classroom while $42 \%$ strongly agreed that they will be able to design SEQUEL based activities for their classroom.

\section{Experience of faculty in implementation}

The participant faculty members implemented some of the activities covered in the workshop in their classroom, and they reported their experience in applying these activities. Following are the quotes from their emails:

"I must appreciate use of SEQUEL simulation for teaching; it's really a potential tool for effective teaching. 
I am using effective teaching methodologies such as flip classroom and they are proving best".

"First of all I would like to thank you for the workshop on Simulation tools. I have evolved as a teacher with respect to usage of simulation tool. I also see myself doing better. Thanks for the sessions on flipped classroom. My students are greatly benefited and find the laboratory sessions very interesting."

\section{LEARNINGS FROM WORKSHOP FOR FUTURE DIRECTION}

In the past, we have conducted a number of workshops (about ten) to familiarize faculty members from various engineering colleges with SEQUEL for teaching electronics circuit concepts. Even though faculty members reported that the workshops helped them to learn the tool, only a small number of them (about 4 out of 200 or 2\%) used the tool in their laboratories as new software. None of them applied this tool as a teaching tool for developing conceptual understanding of students.

Based on this previous experience, we systematically planned the workshop presented here to not only train faculty for designing SEQUEL simulations but also applying them effectively in class. We found that faculty members appreciated the workshop and expressed intention to use simulations in class. Four (out of 15) participants of the workshop implemented SEQUEL based activities in their classroom and reported positive impact on students such as improved interest and motivation in analog circuit problem solving.

This was our first effort to design a workshop on a simulation tool with add-on education technology training. We found that the workshop was effective in terms of faculty perception and their confidence in designing and using SEQUEL based activities.

There are some limitations of our study: Our sample size of this study is small since only 4 members out of 15 actually implemented the activities. In this workshop, we conducted separate sessions on SEQUEL training and pedagogy training but did not collect data on the quality of their SEQUEL based activities. Thus we were not able to provide feedback on their learning from the workshop.

We are in the process of refining our future workshops to bring scalability. We will also introduce a component of formative feedback in our workshop to improve its effectiveness in terms of its usability.

\section{References}

[1] Barron, Ann E., Kate Kemker, Christine Harmes, and Kimberly Kalaydjian, "Large-scale research study on technology in $\mathrm{K}-12$ schools: Technology integration as it relates to the National Technology Standards," Journal of Research on Technology in Education, vol. 35, no. 4 ,pp. 489-507, 2003.

[2] Bauer, John, and Jeffrey Kenton, "Toward technology integration in the schools: Why it isn't happening," Journal of technology and teacher Education, vol. 13, no. 4, pp. 519, 2005.

[3] Blake, Canan, and Eileen Scanlon, "Reconsidering simulations in science education at a distance: features of effective use," Journal of Computer Assisted Learning, vol. 23, no. 6, pp. 491-502, 2007.

[4] Caffarella, Rosemary S., and Lynn F. Zinn, "Professional development for faculty: A conceptual framework of barriers and supports," Innovative Higher Education, vol. 23, no. 4, pp. 241-254, 1999.

[5] Cuban, Larry, Heather Kirkpatrick, and Craig Peck, "High access and low use of technologies in high school classrooms: Explaining an apparent paradox," American educational research journal, vol. 38, no. 4, pp. 813-834, 2001.

[6] De Almeida Amorim, Joni, Izabel de Moraes Sarmento Rego, Jose Macario De Siqueira, and Antonio Martínez-Sáez. "Defining the design parameters of a teacher training course on the incorporation of ICT into teaching practices," Procedia-Social and Behavioral Sciences, 15, pp. 653-657, 2011.

[7] Ertmer, Peggy A, "Teacher pedagogical beliefs: The final frontier in our quest for technology integration?," Educational technology research and development, vol. 53, no. 4, pp. 25-39, 2005.

[8] Frank, Kenneth A., Yong Zhao, and Kathryn Borman, "Social capital and the diffusion of innovations within organizations: The case of computer technology in schools," Sociology of Education, vol. 77, no. 2, pp. 148-171, 2004;

[9] Freeman, Scott, Sarah L. Eddy, Miles McDonough, Michelle K. Smith, Nnadozie Okoroafor, Hannah Jordt, and Mary Pat Wenderoth, "Active learning increases student performance in science, engineering, and mathematics," Proceedings of the National Academy of Sciences, vol. 111, no. 23, pp. 84108415, 2013.

[10] Gülbahar, Yasemin, "Technology planning: A roadmap to successful technology integration in schools," Computers and Education, vol. 49, no. 4, pp. 943-956, 2007.

[11] Harris, Judith, Punya Mishra, and Matthew Koehler. "Teachers' technological pedagogical content knowledge and learning activity types: Curriculumbased technology integration reframed." Journal of Research on Technology in Education, vol. 41, no. 4, pp. 393-416, 2009.

[12] Hew, Khe Foon, and Thomas Brush, "Integrating technology into K-12 teaching and learning: Current knowledge gaps and recommendations for future research," Educational Technology Research and Development, vol. 55, no. 3, pp. 223-252, 2007.

[13] Jimoyiannis, A, and Vassilis Komis, "Computer simulations in physics teaching and learning: a case 
study on students' understanding of trajectory motion," Computers and education, vol. 36, no. 2, pp. 183-204, 2001.

[14] Keengwe, Jared, Grace Onchwari, and Patrick Wachira, "The use of computer tools to support meaningful learning, AACE Journal, vol. 16, no. 1, pp. 77-92, 2008.

[15] Koehler, Matthew J., Punya Mishra, Emily C. Bouck, Michael DeSchryver, Kristen Kereluik, Tae Seob Shin, and Leigh Graves Wolf. "Deep-play: Developing TPACK for 21st century teachers." International Journal of Learning Technology, vol. 6, no. 2, pp. 146-163, 2011.

[16] McKagan, S. B., W. Handley, K. K. Perkins, and C. E. Wieman, "A research-based curriculum for teaching the photoelectric effect," American Journal of Physics, vol. 77, no. 1, pp. 87-94, 2009.

[17] Mishra, Punya, and Matthew Koehler. "Technological pedagogical content knowledge: A framework for teacher knowledge." The Teachers College Record, vol. 108, no. 6, pp. 1017-1054, 2006.

[18] Murthy, Sahana, Sridhar Iyer, and Jayakrishnan Warriem, "ET4ET: a large-scale faculty professional development program on effective integration of educational technology, "Journal of Educational Technology and Society, vol. 18, no. 3 pp. 16-28, 2015.

[19] Nawaz, Allah, and Ghulam Muhammad Kundi. "Digital literacy: An analysis of the contemporary paradigms," International Journal of Science and Technology Education Research, vol. 1, no. 1, pp. 2636, 2010

[20] Patil, M. B., S. P. Das, A. Joshi, and M. Chandorkar, "A new public-domain simulator for power electronic circuits," IEEE Transactions on Education, vol. 45, no. 1, pp. 79-85, 2002.

[21] Physics Education Technology website. (2011). Retrieved 14.04.11.: http://phet.colorado.edu.

[22] Ronen, Miky, and Matzi Eliahu, "Simulation-a bridge between theory and reality: the case of electric circuits," Journal of computer assisted learning, vol. 16, no. 1, pp. 14-26, 2000.

[23] Rutten, Nico, Wouter R. van Joolingen, and Jan T. van der Veen, "The learning effects of computer simulations in science education," Computers and Education, vol. 58, no. 1, pp. 136-153 2012.

[24] Stern, Luli, Nitza Barnea, and Sofia Shauli, "The effect of a computerized simulation on middle school students' understanding of the kinetic molecular theory." Journal of Science Education and Technology, vol. 17, no. 4, pp .305-315, 2008.

[25] Trentin, Guglielmo, "The Xanadu project: training faculty in the use of information and communication technology for university teaching," Journal of computer assisted learning, vol. 22, no. 3, pp. 182196, 2006.

[26] Van Berkum, Jos J A, and Ton De Jong, "Instructional environments for simulations," Education and Computing, vol. 6, no. 3, pp. 305-358, 1991.
[27] Wieman, Carl E., Wendy K. Adams, and Katherine K. Perkins. "PhET: Simulations that enhance learning." Science 322, no. 5902, pp. 682-683, 2008.

[28] Windschitl, M., and Andre, T, "Using computer simulations to enhance conceptual change: the roles of constructivist instruction and student epistemological beliefs," Journal of Research in Science Teaching, vol. 35, no. 2, pp. 145-160. 1998. 